${ }^{I}$ Universidade Federal do Rio de Janeiro (UFRJ),

Núcleo de Experimentações em Etnografia e Imagem,

Rio de Janeiro, RJ, Brasil

tatiana.bacal@gmail.com

Tatiana Bacal'

\title{
BOCA DO LIXO: O FUTURO DA VANGUARDA
}

Boca do Lixo. (1993). Direção de Eduardo Coutinho. 50 min.

Diante do desafio dos limites de uma resenha de um filme com tantas camadas de complexidade, gostaria de pensar sobre o que Eduardo Coutinho, em Boca do lixo(I993), tem a dizer acer- uma "prisão espacial": um lixão em São Gonçalo (Região Metropolitana do Rio de Janeiro), com uma temporalidade determinada - em alguns dias de janeiro, abril e julho de 1992 (mais detalhes em Lins, 2004: 87) -, uma equipe de cinema que vai a um determinado lugar. Segundo Coutinho, "sempre [um] filme começa com as regras do jogo [...] meus filmes começam dizendo que uma equipe de cinema foi a um lugar" (Coutinho, 2008: I49). Mas, neste caso, há uma radical demonstração do dispositivo já que, como afirma Consuelo Lins, é o único filme de Coutinho que não contou com uma pesquisa prévia, "como se o filme contivesse nele mesmo o seu próprio making of" (Lins, 2004: 9I), o que nos leva a perceber uma indisso- 
ciação entre a pesquisa e a filmagem, pois um de seus temas centrais é narrar exatamente esse processo. Outro dispositivo do diretor presente no filme: a importância de manter uma cronologia do processo de filmagem na edição. Significa, neste caso, evidenciar ao público as várias tentativas de aproximação dos personagens. É nesse sentido específico que poderíamos considerar este filme como etnográfico, por ter como base temática as possibilidades e as fragilidades do encontro numa situação complexa.

O processo de pesquisa, tão desvelado em Boca do lixo, cria um sentimento - no campo afetivo mesmo -, de intensa e imediata identificação com o método-pensamento etnográfico (Caiafa, 2007) que reorienta a antropologia a se posicionar na assim chamada virada pós-moderna. "Na pesquisa etnográfica, a participação do etnógrafo naquilo que investiga produz conhecimento, faz avançar a investigação, exprime a relação que o observador-participante estabelece com as pessoas no campo" (Caiafa, 2007: I38). Aqui o termo convivência, experiência compartilhada, um trabalho que resulta e se faz no "contato com outros numa situação privilegiada de observação e participação, e em que o relato desses encontros ocupa um lugar central" (Caiafa, 2007: I38). Um sentimento de identificação que surge de as disciplinas partilharem dos mesmos problemas de trabalho.

A identificação antropológica se dá também no nível da pergunta que orienta o filme de Coutinho. Ele afirma que os seus filmes não são sobre camponeses ou favela ou pobreza. Seus filmes são sobre o encontro, sua ética é comprometida com as pessoas que ele conhece e se tornam personagens de seus filmes. Ele mesmo explica: "o engajamento que há nos meus filmes é uma tentativa de conhecer as razões e versões que andam por aí. É um engajamento ético porque eu tenho que ser leal com as pessoas que eu filmei" (Coutinho, 2008: IOI). Coutinho também afirma que teve a prerrogativa de se interessar por filmar ambientes e pessoas que não interessam a outros cineastas. Além de Boca do lixo ser filmado em um lugar que não interessava a ninguém, este documentário representou um desafio a mais: como filmar (aproximar-se de) pessoas que não querem ser filmadas? Porque não querem ser vistas como e onde estão localizadas, trabalhando num lixão, e porque conhecem bem as imagens negativas veiculadas pela mídia. Nas primeiras tomadas, o espectador se vê diante de uma equipe de três pessoas que chega para filmar, e as respostas iniciais são negativas; a câmera é repudiada numa verdadeira "consciência do estigmatizado sobre o estigma". Jean Rouch, em Les maîtres fous participa do pacto de filmar um ritual no qual um grupo da seita Hauka devora um cachorro, numa devolução ritual dos estereótipos ocidentais sobre a África negra. "Devorar o cachorro" se torna uma metáfora para a demonstração da consciência sobre as relações de poder. As cenas de rostos cobertos com camisas, com mãos sujas que se levantam para cobrir a lente da câme- 
ra, são cenas que revelam todas as camadas de perspectivas em jogo no momento do encontro com a câmera. A consciência do jogo de espelhos da imagem é jogada ao centro dos filmes de Coutinho. "As pessoas lá de baixo pensam que nós não somos civilizados, que somos animais", eis uma das frases de abertura de Santa Marta, duas semanas no morro (I987). Os diferentes jogos de imagem revelam as diferentes versões existentes num determinado ambiente cultural.

Assim, para superar um meio avesso ao olhar dos outros, o cineasta leva uma nova pergunta ao campo. Como diz Coutinho, "fui para o lixo preparado para fazer a seguinte pergunta: 'como é trabalhar no lixo, é bom ou é ruim?'. Quando você está disposto a perguntar se é bom ou se é ruim, surge uma abertura para você ouvir qualquer tipo de resposta. As pessoas intuem o que você quer ouvir" (Coutinho, 2008: 73). Se há uma transformação nos personagens, se a abertura acontece no transcorrer do filme, é através do recurso de demonstrar aos personagens que as suas perguntas são de outra natureza e que a natureza da pergunta reconfigura toda a relação entre o pesquisador/documentarista e os personagens. Se a natureza da pergunta é fundamental para se realizar um filme sobre o trabalho no lixão, "o simples fato de demorar-se naquele lugar ajuda a deslocar a imagem que os catadores têm de quem usa o lixão rapidamente, para 'cobrir' um texto em off" (Lins, 2004: 90). O tempo que se quer permanecer num espaço impensável a fim de ultrapas- sar a barreira do estigma do lixo, do cheiro, das pessoas submetidas a um ambiente intolerável para os olhos dos espectadores é fundamental. A dimensão do tempo compartilhado é um dos fatores mais importantes que diferenciam o tempo da pauta jornalística do tempo do documentarista e também do antropólogo. Transformar a grade de ferro do estereótipo em pergunta aberta e ficar mais tempo no lugar onde ninguém fica é parte da demonstração de que Coutinho e sua equipe estão ali por outros motivos.

Um dos recursos mais interessantes usados por Coutinho e sua equipe neste filme é da imagem fotográfica. Eles tiram fotos de rostos e, com cópias xerox bem ruins, começam a perguntar às crianças, mulheres e homens que se aproximam se reconhecem os seus amigos, os colegas com quem convivem. As fotos são evidenciadas como parte de um exercício de aproximação e de identificação e podem, neste filme, ser consideradas personagens no sentido de que funcionam como ímã, com o objetivo de trazer as pessoas para perto do filme, da equipe e também uns dos outros. Em termos estéticos, os retratos quase apagados das cópias xerox que circulam indicam uma afinidade do documentarista com baixo orçamento, disposto a aprender com os personagens como aproveitar as circunstâncias da melhor forma dentro daqueles limites. Assim, como um pêndulo que retorna a cada personagem, vemos quase a mesma situação em todos os planos; somos levados a acompanhar o diretor tentando se aproximar de 
personagens que passam por uma transformação relacional ao longo do filme. Várias personagens, que falam de costas para a câmera numa primeira abordagem, ficam gradualmente curiosos e se aproximam de Coutinho. E, finalmente, o levam para as suas casas. Coutinho pergunta a Cícera, num determinado momento: "porque Teresa está com vergonha?”, enquanto Teresa cobre o rosto na frente da câmera, e um menino ri ao seu lado, curioso. Cícera responde: "Não sei. Porque ela não gosta, porque diz que vai sair na televisão". Mas arremata: "eu nem ligo... para o que sai na televisão e para o que sai no jornal". Em outra cena, vemos Teresa observando as fotos dela própria com Cícera. Coutinho nos mostra como essa aproximação, com todas as suas nuances e limitações, foi possível.

Se as imagens fotográficas funcionam como personagens, há uma escolha de usar a filmadora como câmera fixa em algumas cenas, principalmente nas casas dos personagens principais. Somos levados a ver como no formato do porta-retrato que nos diz que ali há uma família, há uma casa, há pessoas com sonhos, histórias e desejos. O mosaico que forma, com entrevistas mais curtas e outras mais longas, é de histórias de vida que passam pela migração, em sua maioria do Nordeste para o Sudeste do país, por alternância com trabalhos variados, por pessoas que ali labutam, alguns há muito tempo, outras há pouco, e pela avaliação das diferentes atividades de trabalho. Há pessoas que preferem o lixo a outros serviços, e outros que não se atrevem a se aproximar de lá; alguns que estão desempregados, e também os que vivem do que encontram ali. A presença das imagens para os personagens, bem como da imagem de pessoas e de seus nomes para os espectadores, funcionam como elementos importantes para a formação da identidade e da identificação. Assim, conhecemos a lógica de trabalho e de produção do lixo com a bem-sucedida catadora Nirinha; conhecemos Lúcia e sua personalidade, descontraída no lixo e serena em casa, aquela que nos diz que há uma alegria de compartilhamento e de convivência no lixo, um divertimento que não se sente com a mesma intensidade em casa. A irreverente Cícera, sua filha que sonha ser cantora de música sertaneja. A cena de Cícera a escavar o lixo, vestindo a camiseta com o letreiro "arqueologia", nos mostra essas coincidências ao aproximar a atividade do catador à do arqueólogo, encontrando possibilidades onde aparentemente não há.

Se temos acesso ao ambiente íntimo dos personagens como o espaço da limpeza, da vida em família, da casa, o diretor não esconde o outro ambiente. O lixo é o ambiente que está em relação e convivência com os personagens na maioria das cenas, com muitas imagens de vastas áreas cobertas por todo tipo de rejeitos sujos e perigosos, como a presença espantosa de lixo hospitalar e seringas num lugar em que pessoas não estão protegidas para trabalhar com aquilo. A maioria delas calça chinelos ou sapatos sem muita proteção, as mãos, 
os torsos e os braços descobertos. Os personagens de Coutinho não usam botas e nem uniformes como Estamira, personagem de Marcos Prado, no filme de 2005, uma década depois. São personagens que convivem com o espaço da contaminação social, do perigo, com aquilo que não se come, que se joga fora. Somos obrigados a sair epistemologicamente do âmbito da "pureza" (Douglas, 20r2) e entrar do outro lado, o do perigo social. E ver os personagens de Coutinho como os heróis épicos de criar com o que não se tem, de criar com o que se pensa que não tem, com o que nem se imagina que tem. Pedagógico, o barbudo Enoch, o "Papai Noel", mais próximo de um guru hindu, nos fala que viajou por todo o Brasil, do Acre a Porto Alegre, trabalhando com lixo, na lavoura, nas plantações de café. Nos exibe em sua casa que o relógio na parede encontrado no lixo ganhou nova cola, nova pilha e lá está de novo, funcionando perfeitamente. Ali estão o pôster do filme "Ninja, o guerreiro de ouro", também coletado do lixo, assim como o sofá e outros itens domésticos. Enoch, o naturalista por religião e filosofia, pondera: "porque somos todos da natureza". Há outra seleção em processo acontecendo: o que serve para os animais, o que serve para si, o que serve para outras pessoas. Os critérios do guardar, do reciclar e do vender se recriam nesse momento. Como diz Enoch: "O lixo faz parte da vida. O final do serviço é o lixo. E é dali que começa". Enoch nos ensina que a trajetória dos restos é ainda muito longa, estabelecendo uma outra relação entre natureza e cultura. Citando Klee, Tim Ingold (2012) nos mostra como a "forma é o fim, a morte" enquanto "o dar forma é movimento, ação”, portanto, vida. Assim percebe que ver os fluxos e transformações dos materiais é mais importante para o antropólogo do que o produto final da matéria. Nesse sentido, Enoch nos demonstra que, ao ressignificar o fim de um processo "o lixo é o fim" -, podemos dar início a um novo processo de formação - "É ali que começa" -, trazendo as coisas de volta à vida (Ingold, 20I2).

Outra questão cara ao período em campo é a contradição entre o que as pessoas falam de si e o que elas fazem. Eis um casamento complexo que une observação e conversa. Um dos temas mais difíceis para Coutinho no filme foi tratar da questão de saber se as pessoas comiam os alimentos encontrados no lixão. Jurema é uma das personagens que mais se incomodou com a primeira abordagem de Coutinho. Foi agressiva e irônica. E mais adiante, ela fala que há coisas que se aproveitam do lixo. Cenas justapostas de gente que diz que não come o que encontra no lixo, seguidas por pessoas comendo, deixam claro que entre o falar e o fazer reside grande parte da complexidade do ser humano.

A experiência de pensar Boca do lixo hoje é mais próxima de uma "volta ao futuro" do que de uma visita ao passado. Como uma alucinação, ele nos remete imediatamente ao período presente, o futuro do presente fílmico, funcionando não somente como uma denúncia, mas ganha, com o 
tempo passado, um tom de prenúncio. Impera nesta última década o "espírito de época" de um período de maior intimidade com o que qualificamos como restos - da palavra de ordem da sustentabilidade aliada à cidadania, do uso inteligente de resquícios, de separação individual de cada item do lixo doméstico. E assim, aqueles que aparecem inicialmente como personagens vivendo numa condição sub-humana, desumana, não humana, num salto alucinatório, tornam-se os personagens que dese- jamos imitar no nosso dia a dia. Se, no filme, Coutinho mostra ao espectador a sua luta por encontrar a humanidade em pessoas que vivem em condições sub-humanas - no inimaginável -, se o lixo é a barreira-estigma que deve ser transpassada para um encontro entre o documentarista e as pessoas, os olhos de hoje olham para essas práticas como um modelo a ser copiado.

Recebido em 26/I I/20I5 | Aprovado em 20/OI/20I6

Tatiana Bacal é doutora em Antropologia Cultural pelo Programa de Pós-Graduação em Sociologia e Antropologia da Universidade Federal do Rio de Janeiro (PPGSA/UFRJ) e mestre em Antropologia Social pelo Programa de Pós-Graduação em Antropologia Social do Museu

Nacional/UFRJ. Atualmente realiza pós-doutorado no PPGSA/UFRJ (Bolsista PNPD-CAPES). É coordenadora associada do Núcleo de Experimentações em Etnografia e Imagem (NEXTimagem) da UFRJ. Foi professora do Departamento de Ciências Sociais da PUC-Rio entre 2004 e 20I3. É autora de Música, máquinas e humanos: os DJs no cenário da música eletrônica (20I2) e A MPB em discussão - entrevistas (2006). 


\section{REFERÊNCIAS BIBLIOGRÁFICAS}

Coutinho, Eduardo. (2008). In: Bragança, Felipe (org.). Encontros/Eduardo Coutinho. Rio de Janeiro: Beco do Azougue. Caiafa, Janice. (2007). Aventura das cidades: ensaios e etnografias. Rio de Janeiro: Ed. FGV.

Douglas, Mary. (20I2). Pureza e perigo. São Paulo: Perspectiva.

Gonçalves, Marco Antonio. (2008). O real imaginado. Etnografia, cinema e surrealismo em Jean Rouch. Rio de Janeiro: Topbooks.

Ingold, Tim. (20I2). Trazendo as coisas de volta à vida: emaranhados criativos num mundo de materiais. Horizontes Antropológicos, I8/37, p. 25-44.

Lins, Consuelo. (2004). O documentário de Eduardo Coutinho: televisão, cinema e vídeo. Rio de Janeiro: Zahar. 